\title{
Rapid-sequence MRI for long-term surveillance for paraganglioma and phaeochromocytoma in patients with succinate dehydrogenase mutations
}

\author{
Eleni Daniel 1,2, Robert Jones ${ }^{1,2}$, Matthew Bull ${ }^{3}$ and John Newell-Price ${ }^{1,2}$ \\ ${ }^{1}$ Academic Unit of Diabetes, Endocrinology and Reproduction, Department of Oncology and Metabolism, \\ The Medical School, University of Sheffield, Sheffield, UK, ${ }^{2}$ Department of Endocrinology, and ${ }^{3}$ Department of \\ Radiology, Sheffield Teaching Hospitals NHS Foundation Trust, Sheffield, UK
}

\author{
Correspondence \\ should be addressed \\ to J Newell-Price \\ Email \\ j.newellprice@sheffield.ac.uk
}

\begin{abstract}
Background: Patients with SDHx mutations need long-term radiological surveillance for the development of paragangliomas and phaeochromocytomas, but no longitudinal data exist. The aim of the study was to assess the performance of rapid-sequence non-contrast magnetic resonance imaging (MRI) in the long-term monitoring of patients with $S D H x$ mutations.

Methods: Retrospective study between 2005 and 2015 at a University Hospital and regional endocrine genetics referral centre. Clinical and imaging data of 47 patients with SDHx mutations (SDHB (36), SDHC (6) and SDHD (5)) who had surveillance for detection of paragangliomas by rapid-sequence non-contrast MRI (base of skull to pubic symphysis) were collected.

Results: Twelve index cases (nine $S D H B$, one $S D H C$ and two $S D H D$ ) and 35 mutation-positive relatives were monitored for a mean of 6.4 years (range 3.1-10.0 years). Mean age at the end of the study: SDHB $46.9 \pm 17.6$ years; SDHC $42.3 \pm 24.4$ years; $S D H D 54.9 \pm 10.6$ years. On excluding imaging at initial diagnosis of index cases, 42 patients underwent 116 rapid-sequence MRI scans: 83 scans were negative and 31 scans were positive for sPGL/HNPGL in 13 patients. Most patients had multiple scans ( $n=$ number of patients (number of rapid-sequence MRI scans during screening)): $n=9$ (2), $n=20$ (3), $n=6$ (4), $n=1$ (6). Nine patients (three index) were diagnosed with new paragangliomas during surveillance and non-operated tumour size was monitored in nine patients. There were two false-positive scans $(1.6 \%)$. Scans were repeated every $27 \pm 9$ months.

Conclusions: Biannual rapid-sequence non-contrast MRI is effective to monitor patients with SDHx mutations for detection of new tumours and monitoring of known tumours.

\section{Introduction}

Germ-line mutations of the subunits of the mitochondrial complex II enzyme succinate dehydrogenase (SDHA, SDHB, SDHC, SDHD and SDHAF2), SDHx, are associated with familial paraganglioma (PGL) of the sympathetic chain (sPGL), the parasympathetic chain of the head and neck (HNPGL), and adrenal phaeochromocytoma $(1,2,3,4)$. In general, most phaeochromocytomas secrete catecholamines, whereas sPGLs may be functional or non-secretory, and HNPGLs are usually biochemically silent (5).

$S D H x$ are tumour suppressor genes characterized by loss of heterozygosity in tumour cells due to somatic mutations or loss of expression of the wild-type allele $(6,7)$. The underlying mechanism of tumorigenesis in
() 2016 European Society of Endocrinology Printed in Great Britain
Published by Bioscientifica Ltd. 
SDHx mutations is still unclear, but non-hypoxic HIF1alpha and HIF-2alpha activation is a key feature in pathogenesis ('pseudohypoxia' hypothesis) (8). In SDHxrelated tumorigenesis, there is loss of SDH enzymatic activity and intracellular accumulation of succinate leading to inhibition of prolyl-hydroxylases that usually degrade HIF-1alpha $(9,10,11)$. HIF-1alpha is then able to translocate to the nucleus and activate gene expression promoting angiogenesis, cell survival and glycolysis (10). The role of oxygen-sensing pathways in SDHx tumorigenesis is also supported by observations linking living at high altitude and an increase in disease prevalence and phenotypic severity $(12,13)$.

Patients with $S D H x$ mutations are at a lifelong risk of multifocal, recurrent and malignant PGLs. Mutations in the different subunits cause specific patterns of disease: individuals with paternally inherited SDHD mutations are more likely to develop HNPGL and multifocal disease and less frequently sPGLs $(2,5,14,15)$; SDHB mutation carriers may develop sPGLs that have a higher malignant potential compared with sporadic or other syndromic PGLs (1, 14); SDHC mutations are rare, with affected individuals developing HNPGL and phaeochromocytoma that have a low risk of malignancy. Penetrance may occur over the life course, but is incomplete and variable: some SDHx members of the same family experience either no tumour development or a benign or asymptomatic course, while others develop devastating and aggressive disease. This underscores the need for appropriate biochemical and imaging screening strategies that may be used in an affected individual over their whole life to detect tumour development, as the primary treatment is resection by an expert surgeon and where better outcomes are found when tumours are detected early (16).

Genetic testing for SDHx mutations has been available for approximately the last decade. Although it is widely accepted that carriers of SDHx mutations should be monitored for the penetrance of the disease, there are no studies reporting the outcome of longitudinal monitoring as highlighted in recently published clinical practice guidelines (17). Therefore, we report our longitudinal 10-year experience of surveillance imaging in a large cohort of SDHx patients attending our dedicated endocrine genetics clinic at a University Hospital using rapid-sequence non-contrast magnetic resonance imaging (MRI) as a non-ionizing imaging modality appropriate for lifelong follow-up to address three key clinical questions: (i) does this MRI technique detect new tumours in patients with SDHx?; (ii) can this MRI technique be used to monitor size and extent of known disease in patients in whom definitive surgical excision has not taken place because of tumour site or patient preference? and (iii) what is an appropriate time interval between imaging studies?

\section{Methods}

\section{Patients}

The study was approved as a case notes review by our institutional review board (ID number 3861). All patients with pathogenic SDHx mutations $(n=47)$ attending the dedicated Endocrine Genetics clinic at the Royal Hallamshire Hospital, Sheffield Teaching Hospitals (STH) NHS Foundation Trust, a regional referral centre, from October 2005 to May 2015, were included. A retrospective review of the medical notes, imaging and biochemistry was conducted. All patients were reviewed at each clinic visit by an experienced clinician (JNP). All index cases had either excision of their presenting tumour or other treatment before embarking on surveillance, and the data presented here on imaging are all from the surveillance programme. All mutation-positive relatives had the first surveillance imaging following genetic diagnosis and all their imaging tests are included in the data presented here.

At our institution, genetic testing was performed on patients with phaeochromocytoma aged $<50$ years or a family history suggesting possible genetically driven disease (such as early cardiac death) or in any patient presenting with sPGL or HNPGL. Genetic testing was performed at the accredited regional genetics laboratory as part of the National Genetics Service of the National Health Service, UK. Carriers of SDHD mutations were offered the screening programme if the mutation was of paternal origin, as it is well-documented that only those inheriting an SDHD mutation from their father exhibit clinical manifestations of the syndrome (3).

All data were discussed at the weekly endocrine multidisciplinary team meeting in the presence of an endocrine radiologist, endocrinologists, endocrine surgeons and chemical pathologists, with the outcome of the studies documented as negative (normal screening), positive (paraganglioma present) or requiring further investigations. As there is no gold standard imaging modality that can be used for long-term surveillance, that is without significant radiation exposure and multiple tests, the outcome of this discussion for each scan was collected and analysed. The outcome of a scan was considered false positive if the lesion was not confirmed to be a paraganglioma at subsequent imaging. 


\section{Surveillance protocol}

At baseline, a detailed clinical assessment was made of all newly referred patients, including a detailed clinical history, clinical examination, together with radiological and biochemical investigations. Thereafter, patients were seen approximately yearly for clinical evaluation and biochemical testing (two 24-h collections of urinary fractionated metanephrines measured by highperformance liquid chromatography from 2005 to 2010 or free plasma metanephrines measured by liquid chromatography-tandem mass spectrometry, since 2010) with radiological evaluation every 2 years. For those with disease detected or lesions that require further characterization, further imaging evaluation and clinical assessments were made on an individualized basis.

\section{Imaging}

MR images were acquired from skull base to the pubic symphysis, including all sympathetic and parasympathetic ganglia, on a $1.5 \mathrm{~T}$ Siemens Avanto scanner (Siemens AG Munich) and subsequently reviewed by a single expert endocrine radiologist (MB). The imaging protocol is based on three rapid, unenhanced, non-high-definition sequences (Transverse T1 spin echo in/out phase, Transverse and Coronal T2 Haste). The combination of both T1- and T2-weighted images in two planes gives a survey from skull base to pelvis. Dedicated neck and phased array body coils were used. Parameters for neck imaging: T2 $5 \mathrm{~mm}$ thickness with $1 \mathrm{~mm}$ slice gap TR $3650 \mathrm{~ms}$ TE $99 \mathrm{~ms}$ matrix size $320 \times 70$, T1 $5 \mathrm{~mm}$ thickness with $1 \mathrm{~mm}$ slice gap TR $611 \mathrm{~ms}$ TE $12 \mathrm{~ms}$ matrix size $320 \times 70$. Parameters for chest, abdomen and pelvis imaging: breath hold sequences T2 Haste $7 \mathrm{~mm}$ with $1 \mathrm{~mm}$ slice gap TR $1100 \mathrm{~ms}$ TE $92 \mathrm{~ms}$ matrix size $256 \times 80$, T1 gradient echo $8 \mathrm{~mm}$ thickness with $1 \mathrm{~mm}$ slice gap TR $249 \mathrm{~ms}$ TE $2.29 \mathrm{~ms}$ (out of phase) $4.76 \mathrm{~ms}$ (in phase). Each sequence takes usually $2-3 \mathrm{~min}$ and the average-sized patient requires this to be done in three blocks. There is no requirement for intravenous contrast in the surveillance scans and the total duration of imaging is $25-30 \mathrm{~min}$. Paragangliomas and phaeochromocytomas have high signal on T2-weighted images. The same protocol was used for all patients regardless of causative mutation.

\section{Statistical analysis}

Statistical analysis was performed using one-way ANOVA (GraphPad prism 6.0). Results were reported as mean values \pm one standard deviation. A $P$ value of less than 0.05 was considered significant.

\section{Results}

\section{Patients}

Forty-seven patients with $S D H x$ mutations were included: 36 patients with an $S D H B$ mutation, six with an $S D H C$ mutation and five with an SDHD mutation. Out of 47 patients, 12 were index cases (nine $S D H B$, one $S D H C$ and two $S D H D$ ); the remaining 35 patients were gene-positive relatives. Two patients died during the study, one from complications of metastatic sPGL and one from an unrelated cause. At the end

Table 1 Characteristics of patients with SDHx subunit mutations.

\begin{tabular}{l}
\hline Number of patients (females) \\
Index cases \\
Relatives \\
Age at the end of screening, mean \pm S.D.* \\
Age range \\
Index cases: age range at presentation \\
Mean age at first tumour* (range) \\
Mean duration of screening in years (range) \\
Number of patients who developed tumours in total \\
$\%$ of patients who developed tumours \\
Patients who were diagnosed with tumours on surveillance programme \\
Total number of tumours \\
HNPGL (functioning) \\
sPGL (functioning) \\
Phaeochromocytoma
\end{tabular}

\begin{tabular}{c}
\hline SDHB \\
\hline $36(18)$ \\
9 \\
27 \\
$46.9 \pm 17.6$ \\
$18-76$ \\
$15-50$ \\
$36.1(15-70)$ \\
$6.5(3.0-10)$ \\
11 \\
$31 \%$ \\
4 \\
13 \\
$1(1)$ \\
$12(10)$ \\
0
\end{tabular}

\begin{tabular}{c}
\hline SDHC \\
\hline $6(5)$ \\
1 \\
5 \\
$42.3 \pm 24.4$ \\
$20-75$ \\
37 \\
$48.5(37-60)$ \\
$4.8(3.2-10)$ \\
2 \\
$33 \%$ \\
2 \\
3 \\
$2(1)$ \\
$1(0)$ \\
0
\end{tabular}

\begin{tabular}{c}
\hline SDHD \\
\hline $9(4)$ \\
3 \\
6 \\
$54.9 \pm 10.6$ \\
$26-64$ \\
$12-40$ \\
$33.3(22-56)$ \\
$5.6(2.8-10)$ \\
6 \\
$67 \%$ \\
3 \\
13 \\
$12(0)$ \\
0 \\
1
\end{tabular}

*No statistical difference between the $S D H B, S D H C$ and $S D H D$ groups. 
of the screening period, defined as the time of death $(n=2)$ or May $2015(n=45)$, there was no difference in the mean age between patients with different $S D H$ subunit mutations (SDHB $46.9 \pm 17.6$ years, $S D H C$ $42.3 \pm 24.4$ years and $S D H D 54.9 \pm 10.6$ years, $P=0.5$ ) (this lack of difference may be due to lack of power) (Table 1). There were seven different $S D H B$ mutations, one SDHC and two different SDHD mutations. Mean duration of monitoring for all patients was 6.4 years (range 3.1-10.0 years).
Overall, at any time, 18 patients (12 index cases and six screened relatives) developed either sPGL or HNPGL (SDHB 31\% (11/36), SDHC 33\% (2/6) and SDHD 100\% (5/5)) (Tables 1 and 2). Patients with $S D H B$ mutations predominantly developed sPGLs. Patients with SDHD mutations exclusively developed HNPGLs (5/5 patients) and had multifocal disease $(5 / 5)$ (Table 2). The youngest age at first presentation was 12 years $(S D H D)$ and 15 years $(S D H B)$. At the time of diagnosis of the first tumour, the median age was

Table 2 List of patients with SDHx subunit mutations who developed tumours with characteristics of disease and treatment.

\begin{tabular}{|c|c|c|c|c|c|c|c|}
\hline Patient & Mutation & Age & Tumours & Secretion & $\begin{array}{l}\text { Recurrent/multiple } \\
\text { or metastatic }\end{array}$ & $\begin{array}{l}\text { Size of tumour } \\
(\mathrm{cm})^{\#}\end{array}$ & Treatment \\
\hline $1^{+}$ & $S D H B$ C. $72+1 G>T$ & 15 & Pelvic sPGL & NA & No & $(4.0)$ & Excision \\
\hline $2^{++}$ & $S D H B$ c.600G $>\mathrm{T}$ & $\begin{array}{l}17 \\
24\end{array}$ & $\begin{array}{l}\text { Pelvic sPGL } \\
\text { Abdominal sPGL }\end{array}$ & NA-both & Multiple $(n=2)$ & $\begin{array}{l}(\mathrm{NK}) \\
2.4\end{array}$ & Excision (both) \\
\hline $3^{+}$ & $S D H B$ exon 1 deletion & 50 & HNPGL (GJ) & NA & Locally aggressive & 3.9 & g-knife radiosurgery \\
\hline $4^{+}$ & $S D H B$ C.137G $>A$ & 31 & Abdominal sPGL & NA and DA & No & $(7.0)$ & Excision \\
\hline $5^{+}$ & SDHB c.379dupA & 25 & Abdominal sPGL & NA and DA & No & $(5.0)$ & Excision \\
\hline $6^{++}$ & SDHB c.379dupA & $\begin{array}{l}22 \\
24\end{array}$ & $\begin{array}{l}\text { Abdominal sPGL } \\
\text { Abdominal sPGL }\end{array}$ & NA-both & Multiple $(n=2)$ & $\begin{array}{l}(\mathrm{NK}) \\
2.0\end{array}$ & Excision (both) \\
\hline 7 & SDHB c.379dupA & 20 & Thoracic sPGL & No & No & 2.4 & Excision \\
\hline 8 & SDHB c.379dupA & 68 & Thoracic sPGL* & No & No & 1.2 & $\begin{array}{l}\text { Monitoring for } \\
7 \text { years, no change }\end{array}$ \\
\hline $9^{+}$ & $S D H B$ c.380T > G & 44 & Thoracic sPGL & NA & No & 3.7 & $\begin{array}{l}\text { Monitoring (patient } \\
\text { preference) }\end{array}$ \\
\hline $10^{+}$ & SDHB c.17_42dup26 & 35 & Thoracic sPGL & No & $\begin{array}{l}\text { Metastatic (liver } \\
\text { spine) }\end{array}$ & 8.3 & $\begin{array}{l}\mathrm{I}^{131} \text { MIBG, } \\
\text { radiotherapy, } \\
\text { sunitanib }\end{array}$ \\
\hline $11^{+}$ & SDHB c.17_42dup26 & 70 & Abdominal sPGL & NA & No & $(5.0)$ & Excision \\
\hline \multirow[t]{2}{*}{$12^{++}$} & $S D H C$ c. $39 \overline{7} \mathrm{C}>\mathrm{T}$ & 37 & HNPGL (GJ) & $\mathrm{DA}$ & $\begin{array}{l}\text { Locally aggressive, } \\
\text { progressive } \\
\text { disease }\end{array}$ & $>5.3$ & $\begin{array}{l}\text { Subtotal excision, } \\
\text { excision of } \\
\text { recurrence, g-knife } \\
\text { radiosurgery }\end{array}$ \\
\hline & & 69 & $\begin{array}{l}\text { Recurrence of } \\
\text { HNPGL }\end{array}$ & DA & & & \\
\hline \multirow[t]{2}{*}{13} & SDHC c.397C > T & 60 & HNPGL & No-both & Multiple $(n=2)$ & 2.2 & HNPGL: excision \\
\hline & & & Thoracic sPGL* & & & 2.1 & $\begin{array}{l}\text { sPGL: monitoring-mild } \\
\text { increase in } 5 \text { years }\end{array}$ \\
\hline \multirow[t]{2}{*}{$14^{+}$} & SDHD c. $342 \mathrm{~T}>\mathrm{A}$ & 40 & $\begin{array}{l}\text { HNPGLs } \\
\quad \text { (bilateral CB) }\end{array}$ & No-both & Multiple $(n=3)$ & R: (NK), L: 1.8 & $\begin{array}{l}\text { Right CB: excision, } \\
\text { Left CB: monitoring }\end{array}$ \\
\hline & & & HNPGL (GJ) & & & 1.5 & $\begin{array}{l}\text { GJ: monitoring, } \\
\text { g-knife radiosurgery }\end{array}$ \\
\hline \multirow[t]{2}{*}{15} & SDHDC. $242 C>\mathrm{T}$ & 12 & HNPGL (GJ) & No & $\begin{array}{l}\text { Recurrent, multiple } \\
\quad(n=3)\end{array}$ & 3.5 & $\begin{array}{l}\text { GJ: excision, g-knife } \\
\text { radiosurgery }\end{array}$ \\
\hline & & & $\begin{array}{l}\text { HNPGLs } \\
\quad \text { (bilateral CB) }\end{array}$ & & & $\mathrm{R}: 2.2, \mathrm{~L}: 2.7$ & $\mathrm{CB}$ : monitoring \\
\hline \multirow[t]{2}{*}{$16^{+}$} & SDHDc. $242 C>\mathrm{T}$ & 22 & HNPGL (GJ) & No & $\begin{array}{l}\text { Recurrent, multiple } \\
(n=2), \text { locally } \\
\text { aggressive (GJ) }\end{array}$ & $(\mathrm{NK})$ & $\begin{array}{l}\text { GJ: excision, g-knife } \\
\text { radiosurgery }\end{array}$ \\
\hline & & & HNPGL (CB) & & & $(\mathrm{NK})$ & CB: excision \\
\hline 17 & SDHDc. $242 C>T$ & 31 & $\begin{array}{l}\text { HNPGLs } \\
\quad \text { (bilateral CB) }\end{array}$ & No & $\begin{array}{l}\text { Recurrent, multiple } \\
\quad(n=2)\end{array}$ & R: $1.8, \mathrm{~L}: 1.0$ & $\begin{array}{l}\text { Right: excision } \\
\text { Left: monitoring }\end{array}$ \\
\hline 18 & SDHDc. $242 C>T$ & 56 & $\begin{array}{l}\text { HNPGLs } \\
\quad \text { (bilateral CB) }\end{array}$ & No & Multiple $(n=2)$ & R: 3.0, L: 0.6 & $\begin{array}{l}\text { Right: excision } \\
\text { Left: monitoring }\end{array}$ \\
\hline
\end{tabular}


(all patients (index)): SDHB 28 years old (28), SDHD 31 years old (31).

\section{Rapid-sequence MRI surveillance}

Out of 47 patients, 43 underwent surveillance imaging with rapid-sequence MRI including all 12 index patients; four patients did not have MRI scans due to severe claustrophobia or non-attendance, were imaged by CT and were excluded from the analysis. Excluding any imaging performed during the diagnosis of the index tumours, imaging was performed on the surveillance protocol in the remaining 43 patients who underwent 116 rapid-sequence MRI scans: 83 scans were negative for sPGL/HNPGL and 31 were positive in 13 patients (Fig. 1). At the end of the study, there were no cases of missed PGLs, that is, in patients who developed tumours after the first surveillance MRI $(n=4$; two noradrenaline-secreting sPGLs, one HNPGL confirmed with US and one thoracic non-secreting sPGL confirmed with dedicated MRI imaging), none of the tumours were found to be present on re-review of earlier imaging. A number of radiological tests were performed in patients who had a positive MRI either for further characterization of positive findings or for disease monitoring (CT (eight scans from six patients), USS neck (15 scans from six patients), MIBG (4) and ${ }^{18}$ FDG PET CT (8)) (Table 3). USS neck was used to monitor the size of HNPGLs. Rapid-sequence MRI screening was repeated every $27 \pm 9$ months (median 25 months) and the majority of patients had more than one scan during surveillance ( $n=$ number of patients (number of rapid-sequence MRI scans during surveillance)); $n=9$ (2), $n=20$ (3), $n=6$ (4), $n=1$ (6). The maximum diameter of new tumours diagnosed during surveillance with rapidsequence MRI ranged between 0.6 and $3.5 \mathrm{~cm}$, with no differences in imaging characteristics between $S D H B, S D H C$ and SDHD subunit mutations.

\section{Index cases}

Out of 12 index patients, six had complete surgical resection of sPGLs (all noradrenaline-secreting) confirmed with histology before this study, normal biochemistry and a negative initial rapid-sequence MRI scan at surveillance baseline. Two patients (SDHB) were diagnosed with new sPGLs at the second surveillance MRI (noradrenalinesecreting) and were referred for surgical treatment (Fig. 2 and Table 2).

Four index cases with non-metastatic PGLs were not tumour-free on embarking on surveillance (subtotal resection due to multiple HNPGLs/extensive disease
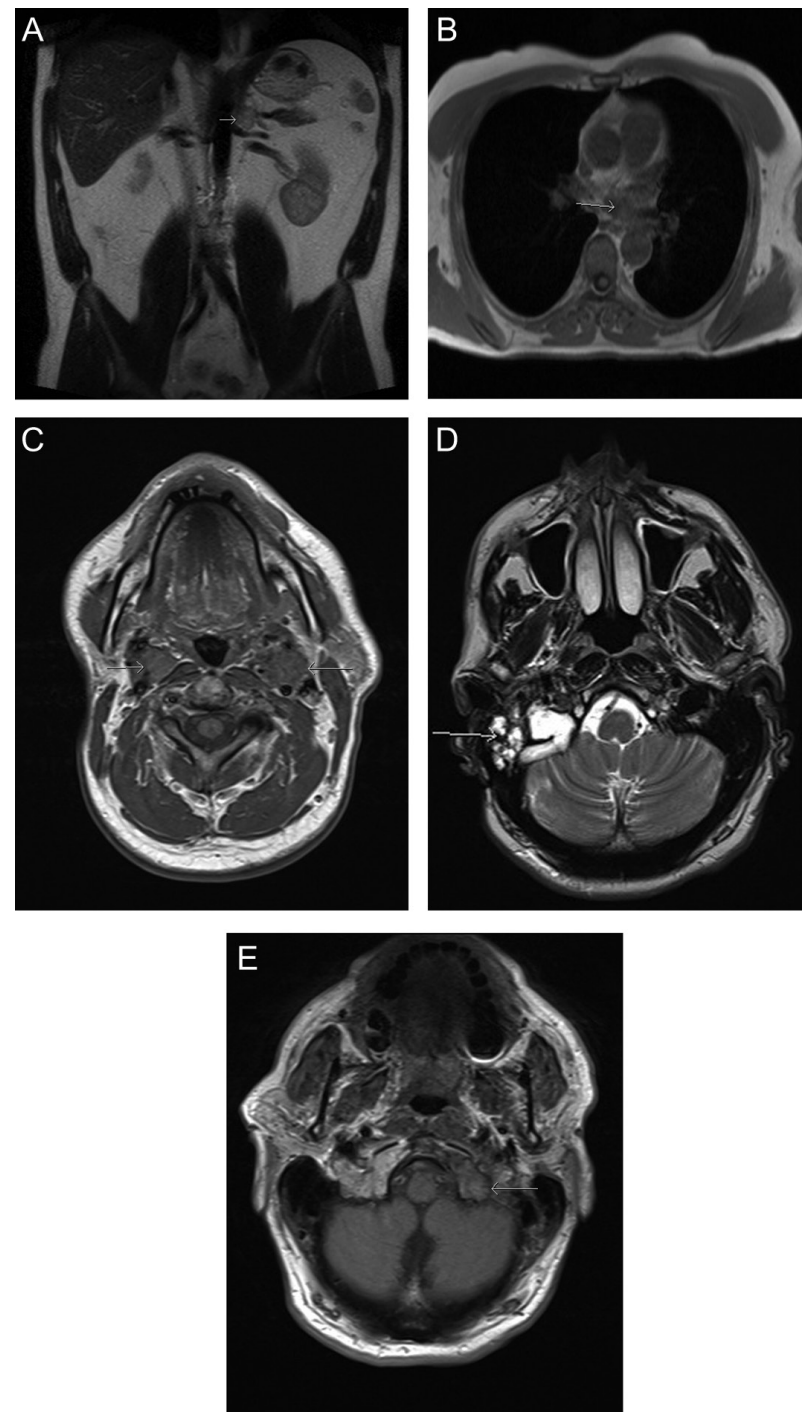

Figure 1

(A) A $20 \mathrm{~mm}$ lesion medial to the left adrenal gland (arrow) shown in a coronal $\mathrm{T} 2$ haste sequence (patient 6 , noradrenalinesecreting abdominal paraganglioma). (B) A $27 \mathrm{~mm}$ soft tissue lesion posterior to the pulmonary artery within the mediastinum (arrow) shown in an axial gradient echo T1-weighted sequence (patient 9, noradrenaline-secreting thoracic paraganglioma). (C) Transverse gradient echo T1 sequence showing bilateral homogenous carotid body tumours at the bifurcation of the common carotid between the internal and the external carotids (arrows) and (D) axial T2 haste sequence showing extensive destructive high-signal tumour (arrow) centred at the right foramen jugulare (patient 15, glomus jugulare and bilateral carotid body tumours). (E) Well-defined homogeneous soft tissue mass centred at the foramen jugulare (arrow) shown in an axial gradient echo T1-weighted sequence (patient 3, noradrenaline-producing glomus jugulare). 
$(n=3$, patients $12,14,16)$ or non-resected disease $(n=1$, patient 9)). The rapid-sequence MRI was used to follow the size of tumours and detect new disease in this group of patients; one patient developed progressive disease and was referred for surgery (patient 12), two patients with HNPGLs (glomus jugulare) showed slow increase in the tumours and referred for radiosurgery (patients 14, 16) and one patient has stable disease (patient 9, sPGL).

There has been histological confirmation of sPGL/HNPGL in all patients who had surgical treatment and in one patient with metastatic disease who had a biopsy $(n=10)$. Although histological confirmation was not made in two other patients, one has a functioning sPGL with characteristic imaging features and diagnostic biochemistry (patient 9) and one patient has a large glomus jugulare tumour with typical radiological features that has been treated with radiosurgery (patient 15). In each case, surgical treatment was either refused by the patient or not appropriate respectively.

\section{Genetically screened relatives}

During surveillance, six genetically screened relatives were diagnosed with either a solitary $(n=4)$ or multiple $(n=2)$

Table 3 The results of additional imaging tests used to investigate positive screening results during monitoring.

\begin{tabular}{|c|c|c|}
\hline & Number of scans & Results \\
\hline Neck USS & 15 & $\begin{array}{l}12 \text { positive (HNPGLs) } \\
3 \text { negative (lymph nodes, } \\
\text { thyroglossal cyst) }\end{array}$ \\
\hline MIBG & 4 & $\begin{array}{l}2 \text { positive } \\
\text { Patient 6: NA-secreting sPGL } \\
\text { Patient 10: non-secreting } \\
\text { metastatic PGL } \\
2 \text { negative } \\
\text { Patient 9: NA-secreting } \\
\text { thoracic sPGL and a HNGPL } \\
\text { Patient 18: non-secreting } \\
\text { multiple HNGPL }\end{array}$ \\
\hline${ }^{18} \mathrm{FDG}$ PET CT & 8 & $\begin{array}{l}3 \text { positive } \\
\text { Patient 11: NA-secreting sPGL } \\
\text { Patient 13: extensive HNPGL } \\
\text { Patient 21: incidental bone } \\
\text { lesion } \\
5 \text { negative } \\
\text { Patient 2: incidental hilar } \\
\text { mass } \\
\text { Patient 7: non-secreting } \\
\text { thoracic sPGL } \\
\text { Patient 8: sPGL } \\
\text { Patient 22: lymphangioma } \\
\text { Patient 23: incidental } \\
\text { lymphadenopathy }\end{array}$ \\
\hline
\end{tabular}

paraganglioma(s) on rapid-sequence MRI. The majority of patients $(5 / 6)$ were diagnosed with PGLs during their first MRI scan (patients 7, 13, 15, 17 and 18). All tumours were non-functioning and there was confirmation from histology (patient 7) or additional dedicated imaging. Except from one patient who underwent surgical excision (patient 7), the tumours were not resected in the remaining four because of the anatomical position, and subsequent MRI scans were used to monitor size and plan management (see below). In one patient (patient 8), a small $(0.6 \times 1.2 \mathrm{~cm})$ thoracic non-functioning sPGL was demonstrated at the second surveillance MRI, 28 months after an initial negative scan. The size of this tumour was also monitored by rapid-sequence MRIs due to the patient not wanting surgical intervention (Fig. 2 and Table 2).

Histological confirmation of a PGL has been made in all genetically screened relatives that had resection in whom the rapid-sequence MRI was deemed consistent with a PGL $(n=5)$. There are two patients with small thoracic non-secreting PGLs who have not had surgery (patients 8 and 13, see below). The diagnosis of sPGL in these patients is based on typical MRI features; FDG-PET was positive in one patient and negative in the second.

\section{Treatment}

Surgical treatment was offered to all patients with non-metastatic sPGL $(n=10$ patients that developed 12 sPGLs). Overall, nine sPGLs were excised in seven patients (all $S D H B$ ), one patient with metastatic disease $(S D H B)$ was treated with chemotherapy and radiotherapy (patient 10), and the disease was monitored with imaging and biochemistry in three patients (two $S D H B$, one $S D H C$; patients 8,9 and 13) (Table 2), with strong patient preference the reason for monitoring instead of surgical treatment; in two patients with non-secreting thoracic sPGLs (patients 8 and 13), this decision was influenced by the high surgical risk due to the presence of co-morbidities and the anatomical challenges of the surgery. There were nine carotid body (CB) tumours in five patients; four patients were managed conservatively with imaging to assess tumour size because of previous surgery for a contralateral $\mathrm{CB}$ tumour $(n=3, S D H D)$ and patient preference $(n=1, S D H D)$. Five patients with glomus jugulare tumours (four index cases) were treated with gamma knife stereotactic radiosurgery (one $S D H B$, one SDHC and three $S D H D$; patients 3, 12, 14, 15 and 16). One patient with a noradrenaline-secreting glomus tumour causing local pressure symptoms had gamma knife stereotactic surgery as surgical intervention was 


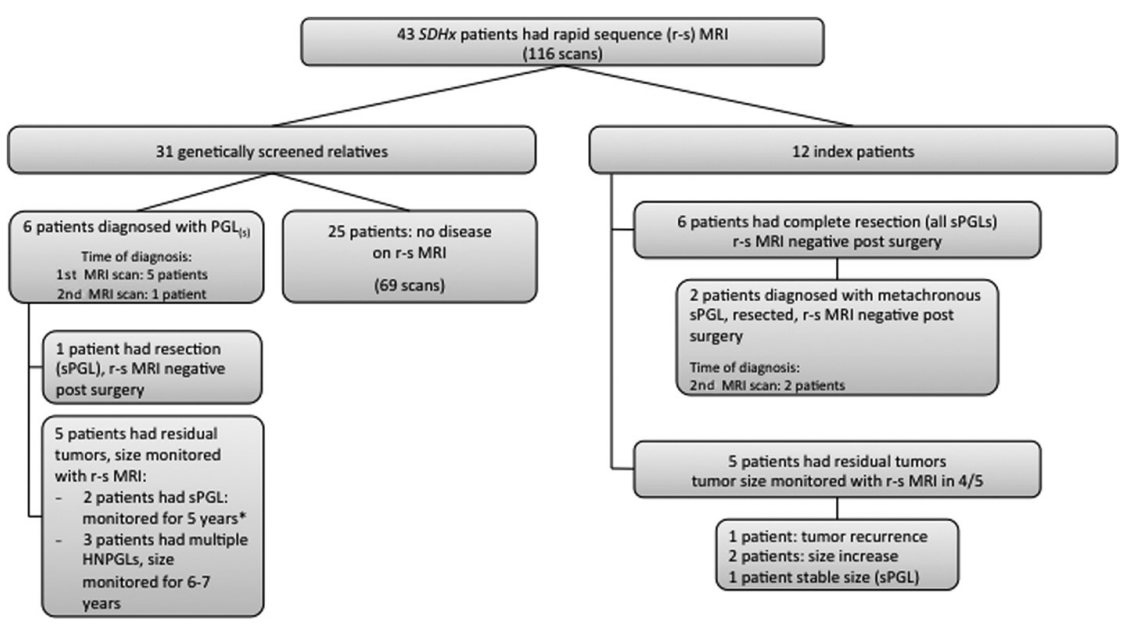

Figure 2

Flow diagram of patient surveillance. considered high risk (patient 3). Following treatment, there was a gradual decrease in the level of catecholamines, with symptoms improved and imaging, which showed reduction in tumour size within 2 years of intervention. A second patient (patient 12, SDHC mutation) with a large HNPGL with intracranial extension was treated with a combination of tumour embolization, surgical resection and radiosurgery to a small bone remnant. Three patients (patients 14, 15 and 16) with multifocal HNPGLs had imaging surveillance followed by gamma knife therapy when an increase in tumour size was detected. Overall, gamma knife therapy led to growth arrest in 4/5 cases and tumour volume reduction in $1 / 5$ and no complications from this intervention in up to 5 years of follow up.

\section{Pituitary adenomas}

The pituitary gland was included in the screening rapidsequence MRI. There were no macroadenomas detected, but 2/43 patients were found to have a small pituitary abnormality and underwent dedicated pituitary imaging revealing microadenomas: both patients carried the $S D H B$ mutation c.379dupA (12\% (2/17) of the carriers in the cohort) aged 67 and 68 years. In both cases, pituitary function was normal and there was no requirement for specific treatment.

Twenty-two patients were found to have incidental findings on MRI during the screening period. Three patients required a referral for a specialist opinion (respiratory physicians for a lung nodule, gynaecologist for an ovarian cyst and breast surgeons), five patients had further imaging for characterization of a benign incidental finding and 14 patients required no further investigations. Two rapid-sequence MRI scans were characterized as false positive based on subsequent imaging; both cases were investigated by dedicated imaging (neck US or MR) that confirmed a lymphangioma and scar tissue respectively.

\section{Discussion}

An increasing number of patients presenting with paragangliomas are being diagnosed with SDHx mutations as genetic testing became standard clinical practice and need surveillance (18) to identify tumours at an early stage when they are amenable to surgical treatment and cure (16). As malignant tumours have been described in children and adolescents, it is common clinical practice to offer genetic testing to relatives of affected individuals from around the second decade of life, with mutation carriers then being offered clinical, radiological and biochemical screening $(15,19)$. For such lifelong screening, it is, therefore, important to minimize cumulative radiation exposure. Recent clinical guidelines emphasize the need for surveillance $(17,20)$. Our data support the use of rapid-sequence MRI for this purpose.

The clinical spectrum of paragangliomas is diverse. Without a clinical screening programme, mutation carriers are at a risk of presenting late with complications of syndromes relating to catecholamine excess, local pressure effects of tumours and malignant and metastatic disease (21). Most tumours are, however, non-functioning and therefore biochemical and clinical monitoring alone is not enough. Measurement of free plasma metanephrines has been reported to be the most sensitive test for functional paragangliomas and phaeochromocytomas (22) combined with the measurement of the dopamine metabolite 3-methoxytyramine as some paragangliomas produce only dopamine (Table 2) (23). For these reasons, our surveillance protocol mandates yearly biochemical and clinical assessment. 
There is a debate as to the gold standard for the detection of paragangliomas. A recent large French series of $S D H x$ mutation carriers showed that a combination of imaging modalities (body CT, Head and neck MRA and octreotide scintigraphy) was 99\% sensitive for paraganglioma detection (24); a sub-analysis of the MRA scans from this study showed that a simplified shorter angio-MRI protocol had similar diagnostic performance to the full imaging protocol and could be used instead for the detection of HNPGLs (25). Although CT has an excellent sensitivity, it involves the use of ionizing radiation and is not ideal for lifelong surveillance. MRI does not involve ionizing radiation and is acceptable for use in younger patients and females of reproductive age, making it an ideal surveillance imaging modality for individuals with $S D H x$ mutations. Shorter scanning protocols to reduce scanning time of whole body MRI have been developed and cross-sectional data show these to be effective in this clinical setting (26). Functional imaging can further characterize any tumour and assess for multifocal or metastatic disease (27). In this context, ${ }^{18} \mathrm{~F}-\mathrm{FDG}$-PET has been used for several years in patients with $S D H B$ mutations and metastatic disease (28), but recently ${ }^{68} \mathrm{Ga}$-DOTATATE PET/CT has been shown to be superior (29). Other compounds such as ${ }^{18} \mathrm{~F}$-fluorodopamine $\left({ }^{18} \mathrm{~F}\right.$-FDA) and ${ }^{18} \mathrm{~F}$-fluorodihydroxyphenylalanine ( ${ }^{18} \mathrm{~F}$-FDOPA) have great promise but are not currently widely available (30). Although ${ }^{123} \mathrm{MIBG}$ imaging is less sensitive than these modalities, it offers a therapeutic option $\left({ }^{131} \mathrm{MIBG}\right)$ in MIBG-avid patients with metastatic disease $(28,31)$.

Our rapid MRI sequences minimize time (skull base to symphysis pubis scanned in less than half an hour), cost (intravenous gadolinium contrast is not used) and provides accurate results; we have not identified a missed case of a paraganglioma using this rapid-sequence MRI for 10 years. Furthermore, our data show that this technique can be used reliably to detect new tumours as well as to monitor tumour growth in patients managed conservatively. Because the majority of tumours detected in our cohort were on first screening of mutation carriers, we suggest that all index case relatives with a positive genetic test are offered imaging at the earliest opportunity, as this is the most likely time that tumours will be detected. For patients who had negative initial screening, use of rapid-sequence MRI approximately every 2 years appears to be effective and clinically safe. Patients with known tumours under surveillance should have individualized follow-up. An association of pituitary tumours and $S D H x$ has been proposed (32), and our MRI protocol allows detection of pituitary tumours of size significant enough to pose a clinical management discussion. Other than the likelihood of the anatomic location of tumours, we found no differences in the MRI features of tumours due to $S D H B, S D H C$ or $S D H D$ mutations.

Gamma knife radiosurgery appears to be an effective treatment option for some patients with HNPGLs where surgery would carry too much morbidity, including those with a previous history of neck surgery (where the predicted postoperative neurological complications are significant) and older patients with significant perioperative risk (33). While we report good outcomes from gamma knife radiosurgery, it is important to note that we are the National Centre for Stereotactic radiosurgery and have treated more than 15000 patients with this technique; it is likely that this high level of expertise had a positive impact on our patient outcomes, and good outcomes and low complications are reported from other high-volume centres (34).

The strengths of this study are that it is a singlecentre study with extensive relevant imaging and clinical expertise, where a practical rapid-sequence MRI imaging protocol has been developed and used for screening for over 10 years, with all cases routinely discussed in multidisciplinary meetings in the presence of endocrine surgeons and input from all specialists' informed management decisions. Although small tumours $(<5 \mathrm{~mm})$ may suffer from partial volume effects limiting the interpretation, the likelihood of tumours of this size causing a clinical syndrome associated with catecholamine excess or being of malignant potential is low. Limitations of our study include the need for multidisciplinary expertise. Although this is a large cohort, the numbers of patients with positive scans remain small precluding statistical comparisons. Furthermore, a single gold standard test that can be used for long-term screening in these patients does not exist, and there is no imaging modality (or combination of modalities) that is without significant radiation exposure and could be used as a comparison; therefore, the outcome of the review of biochemistry, clinical data and MRI imaging by the multidisciplinary team was considered the gold standard to determine the success of treatment and disease-free status. Finally, although two of the patients we describe (patients 8 and 13) have typical radiological features of 
sPGLs, their biochemistry was normal and they have declined surgery, and thus we do not have histological confirmation for them.

To our knowledge, this is the first report of longitudinal screening in patients with SDHx mutations using non-contrast rapid-sequence MRI. Our data support the use of this technique in the surveillance of these patients to detect new tumours and monitor size of existing tumours and provide evidence that biannual imaging with annual biochemical testing is an effective approach.

\section{Declaration of interest}

The authors declare that there is no conflict of interest that could be perceived as prejudicing the impartiality of the research reported.

\section{Funding}

This research did not receive any specific grant from any funding agency in the public, commercial or not-for-profit sector.

\section{Author contribution statement}

E D and J N P analysed the data and wrote the manuscript and all authors edited the manuscript. $\mathrm{M} B$ reviewed all radiological data. E D and $\mathrm{R} J$ collected the data.

\section{Acknowledgements}

The authors are grateful to Marian Schini and Metaxia Tampourlou for assistance with data collection, and the endocrine specialist nurses and staff of the Endocrine Unit for organizing the screening visits.

\section{References}

1 Neumann HP, Bausch B, McWhinney SR, Bender BU, Gimm O, Franke G, Schipper J, Klisch J, Altehoefer C, Zerres K et al. Germ-line mutations in nonsyndromic pheochromocytoma. New England Journal of Medicine 2002346 1459-1466. (doi:10.1056/NEJMoa020152)

2 Baysal BE, Willett-Brozick JE, Lawrence EC, Drovdlic CM, Savul SA, McLeod DR, Yee HA, Brackmann DE, Slattery WH 3rd, Myers EN et al. Prevalence of SDHB, SDHC, and SDHD germline mutations in clinic patients with head and neck paragangliomas. Journal of Medical Genetics 200239 178-183. (doi:10.1136/jmg.39.3.178)

3 Baysal BE, Ferrell RE, Willett-Brozick JE, Lawrence EC, Myssiorek D, Bosch A, Mey Avd, Taschner PEM, Rubinstein WS, Myers EN et al. Mutations in SDHD, a mitochondrial complex II gene, in hereditary paraganglioma. Science 2000287 848-851. (doi:10.1126/ science.287.5454.848)

4 Bayley JP, Devilee P \& Taschner PE. The SDH mutation database: an online resource for succinate dehydrogenase sequence variants involved in pheochromocytoma, paraganglioma and mitochondrial complex II deficiency. BMC Medical Genetics 2005639. (doi:10.1186/1471-2350-6-39)

5 DeLellis RA. Pathology \& Genetics: Tumours of Endocrine Organs. Lyon, France: IARC Press, 2004.

6 Gimm O, Armanios M, Dziema H, Neumann HP \& Eng C. Somatic and occult germ-line mutations in SDHD, a mitochondrial complex
II gene, in nonfamilial pheochromocytoma. Cancer Research 200060 6822-6825

7 Taschner PE, Jansen JC, Baysal BE, Bosch A, Rosenberg EH, Brocker-Vriends AH, van Der Mey AG, van Ommen GJ, Cornelisse CJ \& Devilee P. Nearly all hereditary paragangliomas in the Netherlands are caused by two founder mutations in the SDHD gene. Genes, Chromosomes and Cancer 200131 274-281. (doi:10.1002/gcc.1144)

8 Jochmanova I, Yang C, Zhuang Z \& Pacak K. Hypoxia-inducible factor signaling in pheochromocytoma: turning the rudder in the right direction. Journal of the National Cancer Institute 2013105 1270-1283. (doi:10.1093/jnci/djt201)

9 Gimenez-Roqueplo AP, Favier J, Rustin P, Mourad JJ, Plouin PF, Corvol P, Rotig A \& Jeunemaitre X. The R22X mutation of the SDHD gene in hereditary paraganglioma abolishes the enzymatic activity of complex II in the mitochondrial respiratory chain and activates the hypoxia pathway. American Journal of Human Genetics 200169 1186-1197. (doi:10.1086/324413)

10 Selak MA, Armour SM, MacKenzie ED, Boulahbel H, Watson DG, Mansfield KD, Pan Y, Simon MC, Thompson CB \& Gottlieb E. Succinate links TCA cycle dysfunction to oncogenesis by inhibiting HIF-alpha prolyl hydroxylase. Cancer Cell 2005 7 77-85. (doi:10.1016/j.ccr.2004.11.022)

11 Pollard PJ, El-Bahrawy M, Poulsom R, Elia G, Killick P, Kelly G, Hunt T, Jeffery R, Seedhar P, Barwell J et al. Expression of HIF-1alpha, HIF-2alpha (EPAS1), and their target genes in paraganglioma and pheochromocytoma with VHL and SDH mutations. Journal of Clinical Endocrinology and Metabolism 200691 4593-4598. (doi:10.1210/ jc.2006-0920)

12 Cerecer-Gil NY, Figuera LE, Llamas FJ, Lara M, Escamilla JG, Ramos R, Estrada G, Hussain AK, Gaal J, Korpershoek et al. Mutation of SDHB is a cause of hypoxia-related high-altitude paraganglioma. Clinical Cancer Research 201016 4148-4154. (doi:10.1158/10780432.CCR-10-0637)

13 Astrom K, Cohen JE, Willett-Brozick JE, Aston CE \& Baysal BE. Altitude is a phenotypic modifier in hereditary paraganglioma type 1: evidence for an oxygen-sensing defect. Human Genetics 2003113 228-237. (doi:10.1007/s00439-003-0969-6)

14 Ricketts CJ, Forman JR, Rattenberry E, Bradshaw N, Lalloo F, Izatt L, Cole TR, Armstrong R, Kumar VK, Morrison PJ et al. Tumor risks and genotype-phenotype-proteotype analysis in 358 patients with germline mutations in SDHB and SDHD. Human Mutation 201031 41-51. (doi:10.1002/humu.21136)

15 Astuti D, Hart-Holden N, Latif F, Lalloo F, Black GC, Lim C, Moran A, Grossman AB, Hodgson SV, Freemont A et al. Genetic analysis of mitochondrial complex II subunits SDHD, SDHB and SDHC in paraganglioma and phaeochromocytoma susceptibility. Clinical Endocrinology 200359 728-733. (doi:10.1046/j.13652265.2003.01914.x)

16 Fruhmann J, Geigl JB, Konstantiniuk P \& Cohnert TU. Paraganglioma of the carotid body: treatment strategy and SDH-gene mutations. European Journal of Vascular and Endovascular Surgery 201345 431-436. (doi:10.1016/j.ejvs.2013.01.018)

17 Plouin PF, Amar L, Dekkers OM, Fassnacht M, Gimenez-Roqueplo AP, Lenders JW, Lussey-Lepoutre C, Steichen O \& Guideline Working G. European Society of Endocrinology Clinical Practice Guideline for long-term follow-up of patients operated on for a phaeochromocytoma or a paraganglioma. European Journal of Endocrinology 2016174 G1-G10. (doi:10.1530/EJE-16-0033)

18 Kirmani S \& Young WF. Hereditary paragangliomapheochromocytoma syndromes. In Gene Reviews. Eds RA Pagon, MP Adam, TD Bird, CR Dolan, CT Fong \& K Stephens. Seattle, WA, USA: University of Washington, 1993.

19 Brouwers FM, Eisenhofer G, Tao JJ, Kant JA, Adams KT, Linehan WM \& Pacak K. High frequency of SDHB germline mutations in patients with malignant catecholamine-producing 
paragangliomas: implications for genetic testing. Journal of Clinical Endocrinology and Metabolism 200691 4505-4509. (doi:10.1210/ jc.2006-0423)

20 Lefebvre M \& Foulkes WD. Pheochromocytoma and paraganglioma syndromes: genetics and management update. Current Oncology 2014 21 e8-e17. (doi:10.3747/co.21.1579)

21 Erickson D, Kudva YC, Ebersold MJ, Thompson GB, Grant CS, van Heerden JA \& Young WF Jr. Benign paragangliomas: clinical presentation and treatment outcomes in 236 patients. Journal of Clinical Endocrinology and Metabolism 200186 5210-5216. (doi:10.1210/jcem.86.11.8034)

22 Sawka AM, Jaeschke R, Singh RJ \& Young WF. A comparison of biochemical tests for pheochromocytoma: measurement of fractionated plasma metanephrines compared with the combination of 24-hour urinary metanephrines and catecholamines. Journal of Clinical Endocrinology and Metabolism 200388 553-558. (doi:10.1210/ jc.2002-021251)

23 Eisenhofer G, Goldstein DS, Sullivan P, Csako G, Brouwers FM, Lai EW, Adams KT \& Pacak K. Biochemical and clinical manifestations of dopamine-producing paragangliomas: utility of plasma methoxytyramine. Journal of Clinical Endocrinology and Metabolism 200590 2068-2075. (doi:10.1210/jc.2004-2025)

24 Gimenez-Roqueplo AP, Caumont-Prim A, Houzard C, Hignette C, Hernigou A, Halimi P, Niccoli P, Leboulleux S, Amar L, Borson-Chazot $\mathrm{F}$ et al. Imaging work-up for screening of paraganglioma and pheochromocytoma in SDHx mutation carriers: a multicenter prospective study from the PGL.EVA Investigators. Journal of Clinical Endocrinology and Metabolism 201398 E162-E173. (doi:10.1210/jc.2012-2975)

25 Gravel G, Niccoli P, Rohmer V, Moulin G, Borson-Chazot F, Rousset P, Pasco-Papon A, Marcus C, Dubrulle F, Gouya H et al. The value of a rapid contrast-enhanced angio-MRI protocol in the detection of head and neck paragangliomas in SDHx mutations carriers: a retrospective study on behalf of the PGL.EVA investigators. European Radiology 201626 1696-1704. (doi:10.1007/ s00330-015-4024-5)

26 Jasperson K, Kohlmann W, Gammon A, Slack H, Buchmann L, Hunt J, Kirchhoff A, Baskin H, Shaaban A \& Schiffman J. Role of rapid sequence whole-body MRI screening in SDH-associated hereditary paraganglioma families. Familial Cancer 20131 1-9. (doi:10.1007/ s10689-013-9639-6)
27 Chen H, Sippel RS, O'Dorisio MS, Vinik AI, Lloyd RV \& Pacak K. The North American Neuroendocrine Tumor Society Consensus Guideline for the Diagnosis and Management of Neuroendocrine Tumors: pheochromocytoma, paraganglioma, and medullary thyroid cancer. Pancreas 201039 775-783. (doi:10.1097/ MPA.0b013e3181ebb4f0)

28 Timmers HJ, Kozupa A, Chen CC, Carrasquillo JA, Ling A, Eisenhofer G, Adams KT, Solis D, Lenders JW \& Pacak K. Superiority of fluorodeoxyglucose positron emission tomography to other functional imaging techniques in the evaluation of metastatic SDHBassociated pheochromocytoma and paraganglioma. Journal of Clinical Oncology 200725 2262-2269. (doi:10.1200/JCO.2006.09.6297)

29 Janssen I, Blanchet EM, Adams K, Chen CC, Millo C, Herscovitch P, Taieb D, Kebebew E, Lehnert H, Fojo AT et al. Superiority of [68Ga]DOTATATE PET/CT to other functional imaging modalities in the localization of SDHB-associated metastatic pheochromocytoma and paraganglioma. Clinical Cancer Research 201521 3888-3895. (doi:10.1158/1078-0432.CCR-14-2751)

30 King KS, Chen CC, Alexopoulos DK, Whatley MA, Reynolds JC, Patronas N, Ling A, Adams KT, Xekouki P, Lando H et al. Functional imaging of SDHx-related head and neck paragangliomas: comparison of 18F-fluorodihydroxyphenylalanine, 18F-fluorodopamine, 18F-fluoro-2deoxy-D-glucose PET, 123I-metaiodobenzylguanidine scintigraphy, and 111In-pentetreotide scintigraphy. Journal of Clinical Endocrinology and Metabolism 201196 2779-2785. (doi:10.1210/jc.2011-0333)

31 Taieb D, Timmers HJ, Hindie E, Guillet BA, Neumann HP, Walz MK, Opocher G, de Herder WW, Boedeker CC, de Krijger RR et al. EANM 2012 guidelines for radionuclide imaging of phaeochromocytoma and paraganglioma. European Journal of Nuclear Medicine and Molecular Imaging 201239 1977-1995. (doi:10.1007/s00259-012-2215-8)

32 Xekouki P \& Stratakis CA. Succinate dehydrogenase (SDHx) mutations in pituitary tumors: could this be a new role for mitochondrial complex II and/or Krebs cycle defects? Endocrine-Related Cancer 2012 19 C33-C40. (doi:10.1530/ERC-12-0118)

33 Huy PT, Kania R, Duet M, Dessard-Diana B, Mazeron JJ \& Benhamed R. Evolving concepts in the management of jugular paraganglioma: a comparison of radiotherapy and surgery in 88 cases. Skull Base 200919 83-91. (doi:10.1055/s-0028-1103125)

34 Pollock BE. Stereotactic radiosurgery in patients with glomus jugulare tumors. Neurosurgical Focus 200417 63-67. (doi:10.3171/ foc.2004.17.2.10)

Received 13 July 2016

Revised version received 29 August 2016

Accepted 15 September 2016 